Check for updates

The BMJ

Cite this as: BMJ 2021;373:n1208 http://dx.doi.org/10.1136/bmj.n1208 Published: 11 May 2021

\title{
Covid-19: Government must invest in primary care to aid pandemic recovery, say leaders
}

\section{Gareth lacobucci}

Primary care is under "immense pressure" and needs investment, clear national priorities, and new mechanisms to measure workload in order to restore services and support staff in the aftermath of the covid-19 pandemic, leaders have said.

In a paper ${ }^{1}$ published on 10 May, the NHS Confederation highlighted the increasing and unsustainable workload facing primary care services as they provide routine care while also seeing patients with long covid, those with multiple comorbidities and long term conditions, people waiting for elective care, and the growing number requiring mental health support.

It comes after recent figures from NHS Digital showed that general practices in England delivered nearly three million more appointments in March 2021 compared with March 2019, prompting GP leaders to warn that practices were close to "breaking point."2

Ruth Rankine, director of primary care at the NHS Confederation, said, "Primary care is the front door of the NHS and carries out $90 \%$ of contact with patients, but the challenges it now faces cannot and should not be underestimated.

"Rising demand, growing complexity, higher expectations, increased administrative burden, and the continued challenge of rolling out the largest ever vaccination programme mean primary care is under immense pressure."

The confederation's paper, Restoring Primary Care, outlines 10 urgent priorities for the government to tackle, including:

- Extra investment in infrastructure to make primary care fit for the 21st century, notably in management support, estates, IT, and digital solutions

- Recognition that to deliver patient centred care, different solutions will be required that reflect different population needs and tackle the wider determinants of health. This should include a radical overhaul of the Carr-Hill formula for GP funding

- Clarity on national priorities and transparent analysis of local needs

- A clear set of measures that capture the pressure and workload being put on primary care, perhaps similar to the operational pressures escalation level system used in secondary care

- The need to be open and honest with the public about what is achievable.

Rankine added, "Much of the public debate has been focused on the strain faced by hospitals, but this needs to change. Primary care leaders are committed to working together and doing everything they possibly can for their patients, but an open and honest discussion needs to be had, coupled with a clear set of achievable priorities. Otherwise, there is the risk of care becoming disjointed and services being overwhelmed."

Graham Jackson, senior clinical adviser at the NHS Confederation, said, "Primary care has played a leading role in local responses to covid-19 and over the past year has worked tirelessly and innovatively to serve its patients and communities.

"We must use this opportunity to ensure that we emerge with a renewed focus on the health and wellbeing of our staff, real action on health inequalities, and protect the collaborative working that will underpin future system working."

\section{NHS Confederation. Restoring primary care. www.nhsconfed.org/-/me- dia/Confederation/Files/Publications/Documents/Restoring-primary-care- ten-key-priorities.pdf. \\ 2 lacobucci G. GPs are at "breaking point" and in need of respite, leaders warn. BM/2021;373:n1139. doi: 10.1136/bmi.n1139 pmid: 33947713}

This article is made freely available for use in accordance with BMJ's website terms and conditions for the duration of the covid-19 pandemic or until otherwise determined by BMJ. You may use, download and print the article for any lawful, non-commercial purpose (including text and data mining) provided that all copyright notices and trade marks are retained. 